\title{
Analisis Faktor-Faktor yang Mempengaruhi Prestasi Belajar Taruna Manajemen Transportasi Udara Angkatan II di Politeknik Penerbangan Surabaya
}

\author{
R. Moh. Radix Agustiono \\ Aulia Regia SP \\ Politeknik Penerbangan Surabaya \\ J1. Jemur Andayani 1/73 Wonocolo Surabaya 60236 \\ Telp.(031)841087, Fax.(031)8490005 \\ Email : radixbkd58@gmail.com
}

\begin{abstract}
Achievement of learning achieved by cadets is essentially a reflection of the learning effort. In general the better the learning effort the better the achievements achieved. Of course this is not independent of factors that influence it, among others, interest, motivation, education level of parents, income levels of parents, and so forth. This study discusses the influence factors of interest, motivation, level of old age education, income level of parents, and the number of children dependent parents on learning achievement cadet at Aviation Polytechnic of Surabaya Analysis techniques used descriptive statistical analysis and inferential statistical analysis. Based on the results of descriptive statistical analysis obtained data that cadets air transportation managementat Aviation Polytechnic of Surabaya has (1) interest in learning of $76.53 \%$ included in the high category; (3) parent education level 43,88\% high school education, including in medium category; (4) income level of old roang 50\% having income more than $R p$ 1,000,000, per month, included in high category; and (5) parents of students who have dependents of 3-4 children as much as $44.90 \%$, included in the medium category. The learning achievement of airport electrical cadet at Aviation Polytechnic of Surabaya is classified in very satisfactory category, that is $67.35 \%$ of students have Achievement Index between 2.76 to 3.50 . The result of inferential statistic analysis concludes that interest (X1), learning motivation (X2), parent's education level (X3), parent's income level (X4), and number of parent dependent children (X5) together influence learning achievement $(Y)$ the airport electrical engineering cadet at Aviation Polytechnic of Surabaya shown by the value of Fhitung of 11.275 is greater than the Ftable value of 2.30. The pattern of influence between these six variables is expressed by multiple regression equations: $\mathrm{Y}=1,233+0,011 \mathrm{X} 1+0,014 \mathrm{X} 2+0,004 \mathrm{X} 3+0,005 \mathrm{X} 4+0,002 \mathrm{X} 5$.
\end{abstract}

Keyword: Prestasi Belajar, Motivasi, explanatory research, Manajemen Transportasi Udara.

\section{Latar Belakang Masalah}

Prestasi belajar yang dicapai taruna pada hakekatnya merupakan pencerminan dari usaha belajar. Pada umumnya semakin baik usaha belajar maka semakin baik pula prestasi yang dicapai. Tentunya hal ini tidak terlepas dari faktor-faktor yang mempengaruhinya antara lain minat, motivasi, tingkat pendidikan orang tua, tingkat pendapatan orang tua, dan lain sebagainya.

Minat belajar yang juga merupakan salah satu faktor internal dalam menentukan prestasi belajar, merupakan landasan yang kuat di dalam belajar. Karena dengan adanya minat belajar, taruna akan termotivasi untuk belajar dan akan mampu meraih prestasi yang maksimal. 
Faktor lain yang berpengaruh terhadap prestasi belajar adalah motivasi. Motivasi timbul karena adanya suatu minat. Hurlock (1986), mengartikan minat sebagai sumber motivasi yang akan mengarahkan seseorang pada apa yang akan mereka lakukan bila diberi kebebasan untuk memilihnya. Bila mereka melihat sesuatu itu mempunyai arti bagi dirinya, maka mereka akan tertarik terhadap sesuatu itu yang pada akhirnya nanti akan menimbulkan kepuasan bagi dirinya.

Motivasi merupakan faktor penting yang bersifat non intelektual, yang dapat mendorong taruna mengekspresikan kemampuan dirinya untuk melakukan sesuatu kegiatan belajar sehingga terjadi perubahan perilaku untuk mencapai suatu tujuan berupa prestasi belajar yang tinggi.

Selain minat dan motivasi, faktor tingkat pendidikan orang tua dianggap faktor yang paling berpengaruh terhadap prestasi belajar seseorang, sebab semakin tinggi tingkat pendidikan orang tua, semakin positif sikapnya terhadap peranan kuuliah. Hal ini berarti bahwa tingkat pendidikan ornag tua itu berkorelasi dengan sikap positif terhadap pendidikan. Selain itu, tingkat pendidikan orang tua juga berpengaruh terhadap pekerjaan dan berkorelasi dengan tingkat pendapatan. Semakin tinggi tingkat pendapatan seseorang, maka semakin besar pula penghasilan yang akan diperoleh. Mereka yang berpendidikan tinggi dapat terserap pada sektor-sektor modern (formal) yang memiliki penghasilan yang lebih besar dibanding dengan sektor tradisional (informal).

Begitu juga dengan faktor jumlah anak tanggungan orang tua, merupakan salah satu faktor yang berpengaruh terhadap prestasi belajar, karena jumlah anak tanggungan orang tua yang sedikit di lain pihak dapat berdampak terhadap penyediaan biaya pendidikan bagi anak, sebab semakin sedikit jumlah anak tanggungan orang tua maka semakin besar peluang bagi anak untuk melanjutkan pendidikan sehingga anak dapat mencapai pendidikan yang lebih tinggi, dibandingkan jika jumlah anak tanggungan orang tua banyak.

Bertitik tolak dari upaya untuk menumbuhkan motivasi guna mencapai kinerja yang diharapkan, maka penulis tertarik untuk mengambil judul dalam penelitian ini sebagai berikut : "Analisis faktor-faktor yang mempengaruhiterhadap Prestasi Belajar Taruna Manajemen Transportasi Udara Angkatan II di Politeknik Penerbangan Surabaya”

\section{Metode Penelitian}

\section{Jenis Penelitian}

Berdasarkan tujuan yang ingin dicapai dalam rencana penelitian ini yaitu : menjelaskan pengaruh variabel bebas / independen terhadap variabel terikat / dependen, maka penelitian ini termasuk ke dalam jenis penelitian penjelasan (explanatory research). Penelitian ini berusaha menjelaskan hubungan kausal yang terjadi antara variabel-variabel penelitian dan menguji hipotesa yang telah dirumuskan sebelumnya.

maka yang menjadi populasi dalam penelitian ini adalah manajemen transpotasi udara angkatan II di Politeknik Penerbangan Surabaya.Sehubungan jumlah subyek ( anggota ) didalam populasi tidak begitu banyak maka, penelitian ini dilakukan pada seluruh subyek populasi, artinya 24 taruna manajemen transportasi udara angkatan II di Politeknik Penerbangan Surabaya menjadi obyek atau responden penelitian. Dengan kata lain metode pengambilan sampelnya adalah metode sensus.

\section{Jenis Dan Sumber Data}

Data yang dibutuhkan dalam penelitian ini dapat digolongkan menjadi dua jenisyaitu :

1. Data Primer

Data ini meliputi data tentang prestasi belajartarunamanajemen transportasi udara angkatan II di PoliteknikPenerbangan Surabaya, minatbelajar $\left(\mathrm{X}_{1}\right)$, motivasibelajar $\left(\mathrm{X}_{2}\right)$, tingkat 
pendidikan orang tua $\left(\mathrm{X}_{3}\right)$, pendapatan keluarga $\left(\mathrm{X}_{4}\right)$, dan jumlah anak tanggungan orang tua $\left(\mathrm{X}_{5}\right)$. Data ini diperoleh dari responden yaitu taruna manajemen transportasi adara angkatan II di Politeknik melalui penyebaran kuisioner dan studi dokumentasi.

2. Data sekunder

Data yang dibutuhkan antara lain adalah obyek penelitianya itu Politeknik Penerbangan Surabaya.

\section{Cara Pengumpulan Data.}

Pengumpulan data dilaksanakan dengan mengarahkan kuisioner kepada responden, kuisioner yang sudah diisi diperiksa kembali untuk dipilih kuisioner yang memenuhi syarat dan yang tidak memenuhi syarat dalam pengisiannya.

\section{Hasil Penelitian}

Berdasarkan hasil pengolahan angket secara keseluruhan dapat dilihat pada tabel berikut ini.

Tabel 1

Hasil Pengolahan Angket Minat Belajar Taruna

Manajemen Transportasi Udara Angkatan II

\begin{tabular}{|c|c|c|c|}
\hline Interval & Kategori & Frekuensi & Presentasi \\
\hline $0-20$ & Rendah & 0 & 0 \\
\hline $21-40$ & Sedang & 0 & 0 \\
\hline $41-60$ & Tinggi & 75 & 76,53 \\
\hline $61-80$ & Sangat tinggi & 23 & 23,47 \\
\hline Total & & $\mathbf{9 8}$ & $\mathbf{1 0 0 , 0 0}$ \\
\hline
\end{tabular}

Tabel 2

Hasil Pengolahan Angket Motivasi Belajar taruna Manajemen Transportasi UdaraAngkatan II

\begin{tabular}{|c|c|c|c|}
\hline Interval & Kategori & Frekuensi & Presentase \\
\hline $0-17$ & Rendah & 0 & 0 \\
\hline $18-34$ & Sedang & 0 & 0 \\
\hline $35-51$ & Tinggi & 52 & 53,06 \\
\hline $52-68$ & Sangat Tinggi & 46 & 46,94 \\
\hline Total & & 98 & 100,00 \\
\hline
\end{tabular}

Berdasarkan tabel di atas, maka sebanyak 53,06\% taruna Manajemen Transportasi Udara Angkatan IImemiliki motivasi belajar yang tinggi, dengan niat rata-rata motivasi belajar adalah 51,41

Tabel 3.

Distribusi Frekuensi Tingkat Pendidikan Orang Tua

\begin{tabular}{|c|c|c|}
\hline Tingkat Pendidikan & Frekuensi & Persentase \\
\hline SD & 19 & 19,39 \\
\hline SLTP & 6 & 6,12 \\
\hline SMU & 43 & 43,88 \\
\hline Perguruan Tinggi & 30 & 30,61 \\
\hline
\end{tabular}




\section{Jumlah}

98

100

Dari data yang terlihat pada tabel 40 menunjukkan bahwa proporsi terbanyak adalah mereka yang mempunyai tingkat pendidikan SMU yaitu sebanyak $43,88 \%$ dan nilai 30,61 rata-rata tingkat pendidikan orang tua 12,15 . Dengan demikian dapat disimpulkan bahwa tingkat pendidikan orang tua umumnya tergolong sedang. Hal ini didasarkan pada kategori sebagai berikut :

\begin{tabular}{|l|l|l|}
\hline - SD & $=19,39$ persen & $=$ Rendah \\
\hline - SLTP-SMU & $=50$ persen & $=$ Sedang \\
\hline - Perguruan Tinggi & $=30,61$ persen & $=$ Tinggi \\
\hline
\end{tabular}

Tabel 4

Distribusi Frekuensi Tingkat Pendapatan Orang Tua

\begin{tabular}{|c|c|c|}
\hline Tingkat Pendapatan & Frekuensi & Presentase \\
\hline Kurang dari Rp. 500.000,- & 18 & 18,37 \\
\hline Rp. 500.000- Rp. 1.000.000,- & 31 & 31,63 \\
\hline Lebih dari Rp. 1.000.000,- & 49 & 50,00 \\
\hline Jumlah & $\mathbf{9 8}$ & $\mathbf{1 0 0}$ \\
\hline
\end{tabular}

Tabel 6 menunjukkan bahwa proporsi tertinggi dari responden mempunyai penghasilan lebih dari Rp. 1.000.000.- Nilai rata-rata pendapatan orang tua adalah 902.500. dengan demikian dapat disimpulkan bahwa tingkat pendapatan orangtua tergolong tinggi.

Tabel 5

Distribusi Frekuensi Jumlah anak tanggungan orang tua.

\begin{tabular}{|c|c|c|}
\hline $\begin{array}{c}\text { Jumlah Anak Tanggungan } \\
\text { Orang Tua }\end{array}$ & Frekuensi & Presentase \\
\hline 1-2 orang & 29 & 29,60 \\
\hline 3-4 orang & 44 & 44,90 \\
\hline 5-6 orang & 25 & 25,50 \\
\hline Jumlah & $\mathbf{9 8}$ & $\mathbf{1 0 0}$ \\
\hline
\end{tabular}

Tabel 7 memperlihatkan bahwa sebanyak $44,90 \%$ orang tua mahasiswa mempunyai tanggungan 3-4 orang anai. Nilai rata-rata jumlah anak tanggungan orang tua adalah 3,35. Dapat disimpulkan bahwa rata-rata orang tua mempunyai jumlah anak tanggungan orang tua termasuk dalam kategori sedang.

Tabel 6

Distribusi Frekuensi Prestasi Belajar Taruna

\begin{tabular}{|c|c|c|c|}
\hline Indeks Prestasi & Kriteria & Frekuensi & Persentase \\
\hline $3,50-4,00$ & Dengan pujian & 20 & 20,41 \\
\hline $2,76-3,50$ & Sangat memuaskan & 66 & 67,35 \\
\hline $2,00-2,76$ & Memuaskan & 12 & 12,24 \\
\hline \multicolumn{2}{|c|}{ Jumlah } & $\mathbf{9 8}$ & $\mathbf{1 0 0}$ \\
\hline
\end{tabular}


Berdasarkan tabel 8, sebanyak 67,35\% taruna mempunyai Indeks Prestasi antara 2,76 sampai 3,50 dan hanya 12,24\% taruna yang memiliki Indkes Prestasi 2,00 sampai 2,76. Dapat disimpulkan bahwa Indeks Prestasi Taruna Manajemen Transportasi UdaraAngkatan II berada dalam kategori sangat memuaskan.

\section{Pengaruh Minat, Motivasi, Tingkat Pendidikan Orang Tua, Tingkat Pendapatan Orang Tua, Jumlah Anak Tanggungan Orang Tua Terhadap Prestasi Belajar Taruna Manajemen Transportasi Udara Angkatan II}

Hipotesis yang diajukan adalah "Minat, motivasi, tingkat pendidikan orang tua, tingkat pendapatan orang tua, dan jumlah anak tanggungan orang tua berpengaruh terhadap prestasi belajar Taruna Manajemen Transportasi Udara Angkatan II’.

Secara statistik hipotesis di atas dapat dirumuskan sebagai berikut :

$\mathrm{H}_{0}: \beta_{\mathrm{x} .} 12345=0$

$\mathrm{H}_{1}: \beta_{\mathrm{x}} .12345 \neq 0$

Berdasarkan hasil analisis regresi linier ganda antara pasangan data minat belajar (variable X1), motivasi belajar (variable X2), tingkat pendidikan orang tua (variabel X3), tingkat pendapatan orang tua (variabel X4) dan jumlah anak tanggungan orang tua (variabel X5) dengan prestasi belajar taruna (variabel Y)Manajemen Transportasi Udara Angkatan IIseperti diperlihatkan pada lampiran 05. Diketahui bahwa nilai koefisien regresi ganda $\mathrm{b}_{1=}$ $0,011, b_{2}=0,014, b_{3}=0,004, b_{4}=0,005, b_{5}=0,002$ dengan nilai konstanta a sebesar 1,233. Dengan demikian bentuk pengaruh minat belajar, motivasi belajar, tingkat pendidikan orang tua, tingkat pendapatan orang tua, dan jumlah anak tanggungan orang tua terhadap prestasi belajar taruna Manajemen Transportasi Udara Angkatan II, dapat digambarkan oleh persamaan regresi, yaitu :

$$
\hat{Y}=1,233+0,011 X 1+0,014 X 2+0,004 X 3+0,005 X 4+0,002 X 5
$$

Untuk mengetahui apakah model persamaan garis regresi tersebut dapat digunakan untuk menarik kesimpulan atau apakah persamaan garis regresi yang telah diperoleh signifikan atau tidak, dapat diketahui dengan menggunakan analisis varians (uji F). Rangkuman hasil analisis varians tersebut dapat dilihat pada tabel 9 berikut ini.

Tabel 7

Analisis Varians (ANAVA) Model Regresi Ganda

$$
\hat{Y}=1,233+0,011 \mathrm{X} 1+0,014 \mathrm{X} 2+0,004 \mathrm{X} 3+0,005 \mathrm{X} 4+0,002 \mathrm{X} 5
$$

\begin{tabular}{|l|l|l|l|l|l|}
\hline Variasi & Df & SS & MS & F & Sig \\
\hline Regresion & 5 & 5,447 & 1,089 & 11,275 & 0,000 \\
\hline Residual & 92 & 8,889 & 0,097 & & \\
\hline Total & 97 & 14,335 & & & \\
\hline
\end{tabular}

df = Derajat Kebebasan

SS = Jumlah Kuadrat

MS = Rata-rata jumlah kuadrat

Hasil analisis uji statitik diperoleh nilai $F_{\text {hitung }}$ sebesar 11,275 > nilai $F_{\text {tabel }} F_{0,05(5 ; 92)}$ sebesar 2,30. Ini menunjukkan bahwa koefisien korelasi antara minat, motivasi, tingkat pendidikan orangtua, tingkat pendapatan orangtua dan jumlah anak tanggungan orangtua 
secara bersama-sama mempunyai pengaruh yang signifikan terhadap prestasi belajar tarunaManajemen Transportasi Udara Angkatan II. Dengan demikian hipotesis yang menyatakan minat, motivasi, tingkat pendidikan orangtua, secara bersama-sama berpengaruh terhadap prestasi belajar taruna Manajemen Transportasi Udara Angkatan II diterima dan hasil ujinya dapat dinyatakan signifikan.

Untuk mengtahui besarnya sumbangan efektif minat, motivasi, tingkat pendidikan orangtua, tingkat pendapatan orangtua dan jumlah anak tanggungan orangtua terhadap prestasi belajar taruna dapat dilihat dari koefisien determinasinya $\left(\mathrm{R}^{2}\right)$ sebesar 0,380 . Artinya, jika seluruh Taruna Manajemen Transportasi Udara Angkatan IIditeliti minat, motivasi belajar, tingkat pendidikan orangtua, tingkat pendapatan orangtua, dan jumlah anak tanggungan orangtuanya secara bersama-sama dengan melihat dari prestasi belajar tarunaManajemen Transportasi Udara Angkata II, maka lebih kurang 38 persen ke enam variabel akan mengikuti pola persamaan regresi:

Dengan demikian dapat disimpulkan bahwa besarnya sumbangan efektif minat, motivasi belajar, tingkat pendidikan orangtua, tingkat pendapatan orangtua dan jumlah anak tanggungan orangtua terhadap prestasi belajar tarunaManajemen Transportasi Udara Angkatan IIadalah 38 persen, dalam arti bahwa 62 persen lainnya dipengaruhi oleh variabel lain yang tidak diamati dalam penelitian ini.

$$
\hat{Y}=1,233+0,011 X 1+0,014 X 2+0,004 X 3+0,005 X 4+0,002 X 5
$$

\section{Kesimpulan}

\section{Kesimpulan}

Berdasarkan hasil pengujian hipotesis dan pembahasan hasil penelitian, maka pada bab ini akan diketengahan kesimpulan dan saran penelitian sebagai berikut:

1. Minat belajar taruna Manajemen Transportasi UdaraAngkatan IIsebesar 76,53\% termasuk dalam kategori tinggi.

2. Motivasi belajar taruna Manajemen Transportasi UdaraAngkatan IIsebesar 53,06\% termasuk dalam kategori tinggi.

3. Tingkat pendidikan orangtua taruna Manajemen Transportasi UdaraAngkatan IIsebesar 43,88\% berpendidikan SMU, termasuk dalam kategori sedang.

4. Tingkat pendapatan orangtua taruna Manajemen Transportasi UdaraAngkatan IIsebesar 50\% mempunyai penghasilan lebih dari Rp. 1.000.000,- perbulan, dan tergolong tinggi.

5. Jumlah anak yang menjadi tanggungan orangtua taruna Manajemen Transportasi UdaraAngkatan IIsebesar 44,90\% mempunyai 3-4 orang anak dan termasuk dalam kategori sedang.

6. Prestasi belajar taruna Manajemen Transportasi UdaraAngkatan IItergolong dalam kategori sangat memuaskan, yaitu sebanyak 67,35\% taruna mempunyai Indeks Prestasi antara 2,76 sampai 3,50.

7. Hasil uji statistik diperoleh nilai $F_{\text {hitung }}$ sebesar $11,275>2,30$ nilai $F_{\text {tabel }}$ Dapat disimpulkan bahwa minat, motivasi, tingkat pendidikan orangtua, tingkat pendapatan orangtua, dan jumlah anak tanggungan orangtua berpengaruh terhadap prestasi belajar taruna Manajemen Transportasi UdaraAngkatan II. 


\section{Daftar Pustaka}

Ali, Muhammad, Kamus Lengkap Bahasa Indonesia Modern, Surabaya; PN. Indah, 1995.

Arif Tiro, Muh, Dasar-dasar Statistika, Ujungpandang; Badan Penerbit UNM, 1999.

Arikunto, Suharsimi, Prosedur Penelitian, Bandung: Rineka Cipta, 1992.

Abustam, M. Idrus. 1996. Peranan Keluarga dalam Meningkatkan Kualitas Sekolah. Makalah pada Seminar Sehari dalam Rangka memperingati Hari Guru Nasional tahun 1996 Sulawesi Selatan pada hari Senin, tanggal 2 Desember 1996.

Ahmadi, Abu. 1991. Sosiologi Pendidikan, Jakarta; Rineka Cipta.

Ardhana, W. 1996. Dasar-dasar Kependidikan, Malang; IKIP Malang.

Arikunto, Suharsimi. 1998. Prosedur Penelitian Suatu Pendekatan Praktek, Jakarta: Rineka Cipta.

Darhim, Workshop Matematika, Jakarta: Departemen Pendidikan dan Kebudayaan, 1992.

Depdikbud, Pedoman Umum Sistem Pengujian Hasil Kegiatan Belajar, Jakarta; Departemen Pendidikan dan Kebudayaan, 2003.

Hasan, Iqbal, Pokok-pokok Materi Statistik 2 (Statistik Infrensial), Jakarta: PT Bumi Aksara, 2003. Hamalik, Oemar, Media Pendidikan, Bandung: Rineka Cipta, 1989.

------, Proses Belajar Mengajar, Bandung; Bumi Aksara, 2003.

Mahmud, D. 1989. Psikologi Pendidikan. Jakarta; Dirjen Pendidikan Tinggi. Depdikbud.

Purwanto. M. Ngalim. 1985. Psikologi Pendidikan. Bandung: Remadja Karya.

Siagian, S.P. 1985. Teori Motivasi dan Aplikasinya. Jakarta; Bina Aksara.

Sidi, I.P. 1984. Perkembangan Anak dan Pengaruh Bentuk Keluarga Terhadap Usaha Realisasi Kemampuan Anak (Makalah) dalam buku Keluarga Indonesia Menyambut Tahun 2000: BKKBN.

Slameto. 1995. Belajar dan Faktor-faktor yang Mempengaruhinya. Jakarta: Direka Cipta.

Sukirman. 1995. Analisis Beberapa Faktor terhadap Kesejahteraan Keluarga. Ujungpandang: Tesis PPs UNHAS.

Sudjana, Metoda Statistika, Edisi ke 6, Bandung Tarsito, 1996.

Suherman, Erman dkk., Strategi Pembelajaran Matematika Kontemporer, Bandung; UPI, 2003.

Sugiyono, Statistika untuk Penelitian, Bandung; Alfabeta, 2003.

Suyata. 1996. Peranan Keluarga dalam Meningkatkan Kualitas Sekolah. Makalah untuk Penataran dan Lokakarya Sekolah dan Orangtua (BP3). Jakarta: Direktorat Dokumen.

Tilaar, H.A.R. 1999. Beberapa Agenda Reformasi Pendidikan Nasional dalam Perspektif Abad 21. Jakarta; Tera Indonesia.

Yusuf, Munir.A. 1986. PengantarIlmuPendidikan. Jakarta: Ghalia Indonesia.

Zamroni. 2000. Paradigma Pendidikan Masa Depan, Yogyakarta: Bigraf Publishing. 